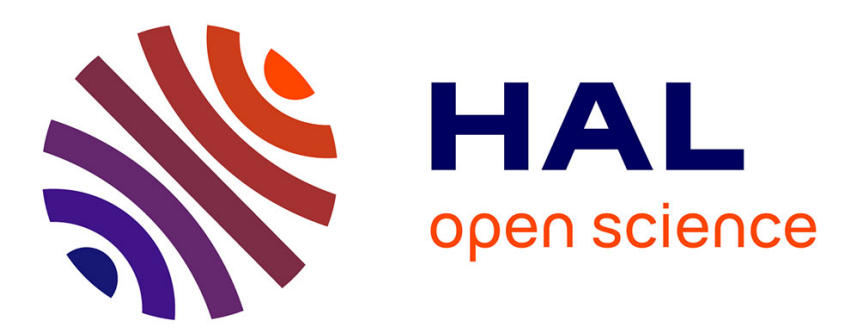

\title{
NC $\alpha$ - gem -dimethylated peptoid side chains: A novel approach for structural control and peptide sequence mimetics
}

\author{
Radhe Shyam, Lionel Nauton, Gaetano Angelici, Olivier Roy, Claude
}

Taillefumier, Sophie Faure

\section{To cite this version:}

Radhe Shyam, Lionel Nauton, Gaetano Angelici, Olivier Roy, Claude Taillefumier, et al.. NC $\alpha$ gem -dimethylated peptoid side chains: A novel approach for structural control and peptide sequence mimetics. Biopolymers, 2019, 110, pp.e23273. 10.1002/bip.23273 . hal-02194898

\section{HAL Id: hal-02194898 \\ https://hal.science/hal-02194898}

Submitted on 13 Oct 2021

HAL is a multi-disciplinary open access archive for the deposit and dissemination of scientific research documents, whether they are published or not. The documents may come from teaching and research institutions in France or abroad, or from public or private research centers.
L'archive ouverte pluridisciplinaire HAL, est destinée au dépôt et à la diffusion de documents scientifiques de niveau recherche, publiés ou non, émanant des établissements d'enseignement et de recherche français ou étrangers, des laboratoires publics ou privés. 


\title{
NC $\alpha$-gem-dimethylated peptoid side chains: a novel approach for structural control and peptide sequence mimetics.
}

\author{
Radhe Shyam, Lionel Nauton, Gaetano Angelici, Olivier Roy, Claude Taillefumier, Sophie Faure \\ Université Clermont Auvergne, CNRS, SIGMA Clermont, ICCF, F-63000 Clermont-Ferrand, France \\ sophie.faure@uca.fr
}

\section{ABSTRACT}

The design of linear peptoid oligomers adopting well-defined secondary structures while mimicking defined peptide primary sequences is a major challenge in the context of drug discovery. To this end, chemists have developed cis-inducing peptoid side chains to build robust PolyProline I-type helices. However, the number of efficient examples remains scarce and chemical diversity accessible through the use of these side chains remains limited. Herein, we introduce an array of $N C \alpha$-gem-dimethylated peptoid residues mimicking proteinogenic amino acids. Submonomer synthesis and block-coupling approaches were explored to access heterooligomers incorporating these novel types of side chains. NMR studies of monomer and trimer models showed that the NCa-gem-dimethylated groups exert a complete cis control on the backbone amide conformation. Lastly, a preliminary molecular modelling study gave an insight into the preferred orientation of the substituents of the $N C \alpha$-gem-dimethyl side chains relative to the peptoid backbone.

\section{INTRODUCTION}

Ever since their initial development in $1992,{ }^{1} \mathrm{~N}$-substituted glycine oligomers or "peptoids", have been considered a highly promising class of protease resistant peptidomimetics due to their close similarity to peptides. Peptoids are sequence-defined oligomers that are generally synthesized by the robust "submonomer method" wherein each peptoid residue is created in two steps: an acylation step to create the peptoid carbon backbone followed by a substitution step using primary amines to install the side chains. ${ }^{2}$ This methodology is particularly well-suited for the preparation of large combinatorial peptoid libraries. ${ }^{3}$ Although chemically similar to peptides, peptoids do not retain their folding properties, primarily due to the absence of backbone intramolecular hydrogen bonding capacity and an achiral backbone. Furthermore, the cis/trans isomerism of the main chain $N, N$ disubstituted amides also contributes to the conformational heterogeneity of the peptoid backbone. This may hamper the development of peptoid ligands with high and selective affinity for biological targets, including the development of folded peptoids as blockers of relevant protein-protein interactions. It is therefore essential to develop strategies for the control of peptoid folding while retaining the unique chemical diversity. Peptoid chemists have developed specific side chains capable of controlling the amide conformation by forming local interactions with the backbone. This has enabled the design of peptoid oligomers exhibiting various privileged secondary structures such as helices (Polyproline type I (PPI), ${ }^{4}$ Polyproline type II (PPII) ${ }^{5}$ and $\eta$-helix ${ }^{6}$ ), ribbons, ${ }^{7}$ loops $^{8}$ and $\Sigma$ strands. ${ }^{9}$ Despite a modest cis-directing control on the tertiary amide bond isomerism, the chiral aromatic phenylethyl side chain (spe) has been used extensively to promote the PPI peptoid helical conformation. Furthermore, its use as helix inducer imposes constraints in term of physicochemical diversity that are a serious brake on the SAR studies. ${ }^{10}$ Other strong cis-inducing peptoid side chains include the chiral aromatic naphthylethyl (s1npe), ${ }^{11}$ the triazolium-type side chain, ${ }^{12}$ the chiral aliphatic tert-butylethyl (s1tbe), ${ }^{13}$ and the achiral aliphatic tert-butyl $(t \mathrm{Bu})^{14}$ and fluoro-alkyl groups. ${ }^{15}$ 
In order to increase chemical diversity, functionalized chiral phenylethyl side chains carrying different substituents on the aromatic core have been developed. ${ }^{16}$ However, neither these highly hydrophobic side chains nor the triazolium-type side chains represent optimal mimetics of amino acid side chains. ${ }^{17}$ Among the cis-inducing peptoid side chains, the tert-butyl side chain is unique since it induces complete cis conformation via steric effects, regardless of the nature of the solvent (Figure 1A). ${ }^{14,18} \mathrm{In}$ addition, despite the absence of chirality, a network of weak interactions such as intramolecular $\mathrm{CO}(i) \cdots \mathrm{HC}(i-\mathrm{n})(\mathrm{n}=1,2$ or 3$)$ hydrogen bonds and $i / i+3 t \mathrm{Bu} \cdots t \mathrm{Bu}$ London interactions help the folding of $N t \mathrm{Bu}$ peptoid oligomers into the PPI-like helical conformation (Figure 1B). ${ }^{19}$

(A)

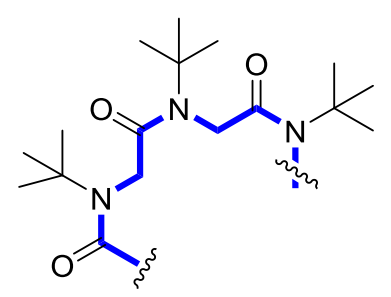

all-cis
(B)

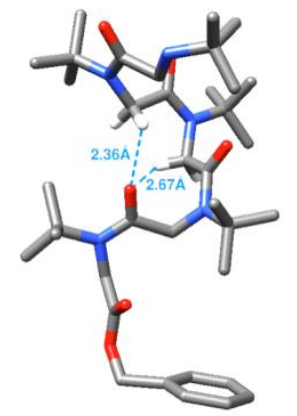

FIGURE 1 (a) Peptoid oligomer carrying the tert-butyl side chain; (b) X-Ray structure of the pentamer Ac- $(\mathrm{N} t \mathrm{Bu})_{5}-\mathrm{OBn}^{19}$

Through the design of $N C \alpha$-gem-dimethylated $N$-substituted glycine monomers mimicking natural amino acids (Figure 2), we herein address the challenge of controlling the amide bond isomerism while retaining the chemical diversity. These novel side chains may be regarded as "functionalized" tert-butyl side chains and we therefore speculated that they would likewise induce a high or even complete cis-amide control.

(A)<smiles>[R]C(C)(C)N(CC(=O)N(C)C)C(=O)CN(C)C(=O)CC</smiles>

(B)<smiles>CC(C)(C)C</smiles>

$t \mathrm{Bu}=$ NghAla

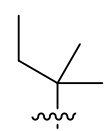

Nglle

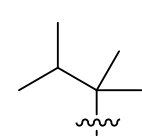

NgLeu<smiles>CC(C)(C)Cc1c[nH]c2ccccc12</smiles>

NghTrp<smiles>CC(C)(C)CC(C)(C)Cc1ccc(O)cc1</smiles>

NghTyr<smiles>CC(C)(C)C(C)(C)C(=O)O</smiles>

NgAsp<smiles>CC(C)(C)C(C)(C)CC(=O)O</smiles>

NgGlu<smiles>CC(C)(C)Cc1c[nH]cn1</smiles>

$\mathrm{NghHis}$
NgPhe<smiles>CC(C)(C)CCCCN</smiles>

NgLys<smiles>CC(C)(C)C(C)(C)CO</smiles>

NghSer<smiles>CC(C)(C)CC(N)=O</smiles>

NgGln

FIGURE 2 (a) Generic structure of a peptoid residue carrying a "substituted" tert-butyl side chain and its cis/trans isomerism; (b) Structures of a library of $\alpha, \alpha$-gem-dimethylated side chains mimicking proteinogenic amino acids side chains and proposed peptoid residue nomenclature (the $g$ letter refers to $\alpha, \alpha$-gem-dimethyl and the $h$ letter refers to homo)

The gem-dimethyl moiety is a special feature encountered in many natural products such as taxanes, epothilones or macrolides. ${ }^{20}$ Furthermore, the gem-dimethyl group has been successfully introduced in biologically relevant compounds in order to enhance specific therapeutic effects (bioavailability, 
potency, selectivity, toxicity). In the field of peptides and peptidomimetics, the Thorpe-Ingold effect of the gem-dimethyl group has been exploited for the conformational restriction of peptide oligomers through the use of $\alpha$-aminoisobutyric acid (Aib). ${ }^{21}$ As mentioned above, we speculated that the steric restriction generated by the $N C \alpha$-gem-dimethyl group should block the peptoid backbone amide in the cis conformation. Herein we thus show that a large array of cis inducing side chains closely mimicking natural amino acids side chains could be designed and introduced into peptoid oligomers.

\section{MATERIALS AND METHODS}

\subsection{Materials}

Chemicals obtained from commercial sources were used without further purification unless stated otherwise. tert-Butylamine (98\% purity), tert-amylamine (98\% purity), 2-amino-2-methyl-1-propanol (99\% purity) and diphenylphosphinic acid pentafluorophenyl ester were purchased from Aldrich. Benzyl bromoacetate (97\% purity), ethyl bromoacetate (98\% purity) and bromo acetylbromide (98\% purity) were purchased from Alfa aesar. tert-Butylbromoacetate (98\% purity) was purchased from TCI. Piperidine (99\% purity) was purchased from Avocado. THF, $\mathrm{CH}_{2} \mathrm{Cl}_{2}$ and $\mathrm{MeOH}$ were dried over aluminum oxide via a solvent purification system and stored over $4 \AA$ molecular sieves. EtOAc, $\mathrm{CH}_{2} \mathrm{Cl}_{2}$, cyclohexane, and $\mathrm{MeOH}$ for column chromatography were obtained from commercial sources and were used as received. $\mathrm{Et}_{3} \mathrm{~N}$ was dried over $\mathrm{KOH}$, distilled and stored over $4 \AA$ molecular sieves.

\subsection{Preparation of $\alpha, \alpha$-gem-dimethylated amines}

The required $N C \alpha$-gem-dimethylated amines a-g (Figure 3) were purchased or prepared in gram scale (Supporting Information Scheme S1, S2 and S3).
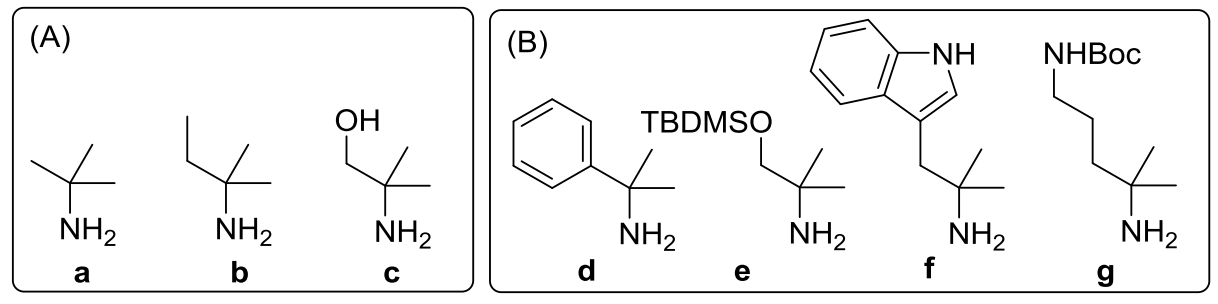

FIGURE 3 List of the $\alpha, \alpha$-gem-dimethylated amines used in the present study: (A) commercially available and (B) amines prepared by synthesis

\subsection{Preparation of peptoid monomer models carrying $N C \alpha$-gem-dimethylated side chains}

To a solution of piperidine (1.0 equiv, $0.2 \mathrm{M})$ in THF at $0{ }^{\circ} \mathrm{C}$ under $\operatorname{argon}$ was added $\mathrm{Et}_{3} \mathrm{~N}$ (1.2 equiv) and then bromoacetyl bromide (1.2 equiv). After stirring for $1 \mathrm{~h}$ at $0^{\circ} \mathrm{C}$, the resulting mixture was diluted with EtOAc $(10 \mathrm{~mL}$ per mmol of starting material) and filtered, washing the solids with EtOAc. The filtrate was then concentrated and dried in vacuo, yielding $N$-(2-bromo-1oxoethyl)piperidine which was purified by flash chromatography on silica gel using EtOAc/cyclohexane 50:50 as eluent. To a solution of the bromoacetyl amide (1.0 equiv, $0.2 \mathrm{M}$ ) in THF at $0{ }^{\circ} \mathrm{C}$ under argon was added $\mathrm{Et}_{3} \mathrm{~N}$ (2.0 equiv) followed by the chosen $\alpha, \alpha$-gem-dimethylated amine (4.0 equiv). After stirring overnight at room temperature, the resulting mixture was diluted with EtOAc $(10 \mathrm{~mL}$ per mmol starting material) and filtered, washing the solids with EtOAc. The filtrate was then concentrated under reduced pressure. When the primary amine used could not be removed by simple evaporation, the product was purified by flash chromatography on silica gel. The secondary amine was then acetylated with acetic anhydride (4.0 equiv) and $\mathrm{Et}_{3} \mathrm{~N}\left(2.0\right.$ equiv) in EtOAc at $0{ }^{\circ} \mathrm{C}$ 
overnight. The resulting mixture was diluted with EtOAc $(10 \mathrm{~mL}$ per mmol starting material) and filtered, washing the solids with EtOAc. The filtrate was then concentrated and dried in vacuo, and the crude monomeric peptoid model was purified by flash chromatography on silica gel.

\subsection{Submonomer synthesis of peptoid oligomers}

\subsubsection{Substitution step}

To a solution of tert-butyl bromoacetate, benzyl bromoacetate, ethyl bromoacetate or bromoacetyl amide (1.0 equiv, $0.2 \mathrm{M}$ ) in THF at $0{ }^{\circ} \mathrm{C}$ under argon was added $\mathrm{Et}_{3} \mathrm{~N}$ (2.0 equiv) followed by the chosen primary amine (4.0 equiv). After stirring overnight at room temperature, the resulting mixture was diluted with EtOAc (10 mL per mmol starting material) and filtered, washing the solids with EtOAc. The filtrate was then concentrated under reduced pressure. EtOAc was added to the residue which was then concentrated under reduced pressure. When the primary amine used could not be removed by simple evaporation under reduced pressure, the product was purified by flash chromatography on silica gel.

\subsubsection{Acylation step}

To a solution of the crude secondary amine $(1.0$ equiv, $0.2 \mathrm{M})$ in EtOAc at $0^{\circ} \mathrm{C}$ under argon, was added $\mathrm{Et}_{3} \mathrm{~N}$ (1.2 equiv) and then a solution of freshly prepared bromoacetic anhydride (1.2 equiv) in EtOAc. After stirring for $2 \mathrm{~h}$ at room temperature the resulting mixture was filtered, washing the solids with EtOAc. The filtrate was then concentrated and dried in vacuo. Flash chromatography on silica gel yielded the desired bromoacetyl amide.

\subsubsection{N-terminal acetylation}

To a solution of the peptoid (1.0 equiv) and $\mathrm{Et}_{3} \mathrm{~N}$ (4.0 equiv) in EtOAc $(0.2 \mathrm{M})$ at room temperature was added acetic anhydride ( 8.0 equiv). After stirring overnight at room temperature, the mixture was filtered, washing the solids with EtOAc. The filtrate was then concentrated and dried in vacuo, yielding the crude $N$-acylated compound. The final oligomer was purified by flash chromatography on silica gel.

2.5 Access to peptoid oligomers by blockwise coupling approach

\subsubsection{General procedure of coupling with pentafluorophenyl diphenyl phosphinate (FDPP)}

The required free-acid block peptoid oligomer was obtained by hydrogenolysis of the benzyl ester precursor using $\mathrm{Pd} / \mathrm{C} 10 \%$ in methanol. To a solution of the free-acid block peptoid oligomer (1.0 equiv., $0.4 \mathrm{M})$ in dry $\mathrm{CH}_{2} \mathrm{Cl}_{2}$ at room temperature under argon was added FDPP (1.2 equiv). The mixture was stirred for $5 \mathrm{~min}$ and a solution of the free-amine block peptoid oligomer (1.0 equiv., $0.4 \mathrm{M}$ ) and $\mathrm{DBU}$ (3.0 equiv.) in $\mathrm{CH}_{2} \mathrm{Cl}_{2}$ was slowly added dropwise. The resulting mixture was stirredat room temperature for $48 \mathrm{~h}$ and was then diluted with $\mathrm{CH}_{2} \mathrm{Cl}_{2}$ and subsequently washed with $5 \%$ aq. citric acid solution and satd. aq. $\mathrm{NaHCO}_{3}$. The organic fraction was dried over $\mathrm{Na}_{2} \mathrm{SO}_{4}$, filtered and concentrated in vacuo, yielding the crude product. The products were purified by flash chromatography on silica gel column.

\subsubsection{General procedure of coupling with pentafluorophenyl trifluoroacetate (TFAPfp)}

The required free-acid block peptoid oligomer was obtained by hydrogenolysis of the benzyl ester precursor using $\mathrm{Pd} / \mathrm{C} 10 \%$ in methanol. To a solution of the free-acid block peptoid oligomer (1.0 
equiv., $0.3 \mathrm{M}$ ) in dry $\mathrm{CH}_{2} \mathrm{Cl}_{2}$ at room temperature under argon was added pentafluoropheny trifluoroacetate (1.5 equiv.) and pyridine (1.5 equiv.). The mixture was stirred for 1 hand was then diluted with $\mathrm{CH}_{2} \mathrm{Cl}_{2}$ and washed with $1 \mathrm{M} \mathrm{HCl}$ and satd.aq. $\mathrm{NaHCO}_{3}$. The organic fraction was dried over $\mathrm{Na}_{2} \mathrm{SO}_{4}$, filtered and concentrated in vacuo, yielding the crude activated ester which was immediately used in the next step. To the solution of the activated ester (1.0 equiv., $0.2 \mathrm{M}$ ) in dry $\mathrm{CH}_{2} \mathrm{Cl}_{2}$ at room temperature under argon was added slowly a solution of the free-amine block peptoid oligomer (1.0 equiv., $0.2 \mathrm{M}$ ) and $\mathrm{DBU}$ (3.0 equiv.) in $\mathrm{CH}_{2} \mathrm{Cl}_{2}$. The mixture was stirred for $48 \mathrm{~h}$ and was then diluted with $\mathrm{CH}_{2} \mathrm{Cl}_{2}$ and subsequently washed with $5 \%$ aq. citric acid solution and satd. aq. $\mathrm{NaHCO}_{3}$. The organic fraction was dried over $\mathrm{Na}_{2} \mathrm{SO}_{4}$, filtered and concentrated in vacuo, yielding the crude product. The products were purified by flash chromatography on silica gel column.

\subsection{Mass spectrometry}

LC-MS were recorded on a Micromass Q-Tof Micro (3000 V) apparatus or a Q Exactive QuadrupoleOrbitrap Mass Spectrometer coupled to a UPLC Ultimate 3000 (Kinetex EVO C18; $1.7 \mu \mathrm{m} ; 100 \mathrm{~mm}$ x $2.1 \mathrm{~mm}$ column with a flow rate of $0.45 \mathrm{~mL} \cdot \mathrm{min}^{-1}$ with a linear gradient of solvent $\mathrm{B}$ from $5 \%$ to $95 \%$ over 7.5 min (solvent $\mathrm{A}=\mathrm{H}_{2} \mathrm{O}+0.1 \%$ formic acid, solvent $\mathrm{B}=$ acetonitrile $+0.1 \%$ formic acid); equipped with a DAD UV/VIS 3000 RS detector).

\subsection{Nuclear magnetic resonance spectroscopy}

NMR spectra $\left({ }^{1} \mathrm{H},{ }^{13} \mathrm{C}\right.$, Jmod, COSY, HSQC, HMBC) were recorded on a Bruker AC 400 spectrometer or a Bruker AC-500 spectrometer. Chemical shifts were referenced to the residual solvent peak and coupling values $J$ were given in Hz. The following multiplicity abbreviations were used: $\mathrm{s}$ for singlet, $\mathrm{bs}$ for broad singlet, $\mathrm{d}$ for doublet, $\mathrm{t}$ for triplet, $\mathrm{q}$ for quartet and $\mathrm{m}$ for multiplet. Assignments were based on the following 1D and 2D experiments: ${ }^{1} \mathrm{H}, \mathrm{COSY}, \mathrm{HMBC}, \mathrm{HSQC}$ and $J$ mod-experiments.

\subsection{Molecular modelling}

Gas-phase full geometry optimizations and scans were performed at the density functional theory (DFT) level using B3LYP functional with $6-31+\mathrm{G}(\mathrm{d}, \mathrm{p})$ basis sets. All the DFT calculations were carried out with Gaussian09 software. ${ }^{22}$ Structure preparations and visualizations were performed using chimera software. ${ }^{23}$

On peptoid monomer models, a $360^{\circ}$ scan of the dihedral angle $\chi 1$ was performed by intervals of $5^{\circ}$ at the B3LYP/6-31+G(d,p) level. Molecular dynamics was performed using NAMD $^{24}$ and the charmm $22^{25}$ force field parameters. A hexamer model was constructed after parametrization of each side chain with Gaussian 09 and using the paratool module from VMD (visual Molecular Dynamic). ${ }^{26}$ For the initial construction, the $\omega$ dihedral angles were considered to be $0^{\circ}$ (cis conformation), the $\varphi$ dihedral angles were considered to be $-90^{\circ}$ and the $\psi$ dihedral angles were considered to be $\pm 180^{\circ}$. The $\chi 1$ angle values were chosen to correspond one of the most stable positions identified during the $\chi 1$ scan of monomer models; for the tert-butyl side chain $\left(\chi 1=+60^{\circ}\right)$, for the $N g$ Ile side chain $\left(\chi 1=-60^{\circ}\right)$ and for the $N g$ Phe side chain $\left(\chi 1= \pm 180^{\circ}\right)$.The hexamer was capped with an $N$-terminal acetyl group and a $C$-terminal benzyl ester. The molecular dynamics (MD) simulation included an initial phase of minimization followed by $40 \mathrm{~ns}$ of simulation. MD simulation was performed in gas with a dielectric constant of 37.5 corresponding to acetonitrile as solvent, at a temperature of $298 \mathrm{~K}$.

\section{RESULTS AND DISCUSSION}


A large number of $\alpha, \alpha$-gem-dimethyl primary amines are commercially available, including those that are necessary for mimicking the side chain of naturally-occurring amino acids (Figure 2). In the present study, six different $N C \alpha$-gem-dimethyl side chains were installed and their capacity to control the backbone amide conformation was studied. These six side chains originated from the use of tertbutylamine a, 1,1-dimethylpropylamine b, 2-amino-2-methyl-1-propanol c, $\alpha, \alpha$-dimethylbenzylamine d, $\alpha, \alpha$-dimethyl- $1 H$-indole-3-ethanamine f and tert-butyl $N$-(4-amino-4-methylpentyl) carbamate $\mathbf{g}$ (Figure 3). Although commercially available, amines $\mathbf{d}, \mathbf{f}$ and $\mathbf{g}$ were prepared on gram-scale according to known procedures (Supporting Information).

We first synthesized a series of peptoid monomer models carrying these novel side chains in order to study their capacity to control the peptoid amide geometry. The cis-directing effect of these new side chains was thus assessed using a $C$-piperidinyl amide monomer model capped with an acetyl group at the $N$-terminus (Scheme 4). This peptoid model has previously proven to be well suited for the determination of amide cis/trans ratios. ${ }^{11-15}$ The cis/trans ratio of the acetamide may indeed be investigated by NMR spectroscopy since the cis and trans rotamers display distinct ${ }^{1} \mathrm{H}$ NMR resonances which allows for determining $K_{\text {cis/trans }}$ ratios. ${ }^{11,12}$ Starting from $N$-(2-bromo-1-oxoethyl) piperidine, bromine substitution with an excess of primary amine in the presence of triethylamine followed by acetylation provided the monomeric models carrying a selection of "functionalized" tertbutyl side chains in moderate to good yields (Scheme 1).

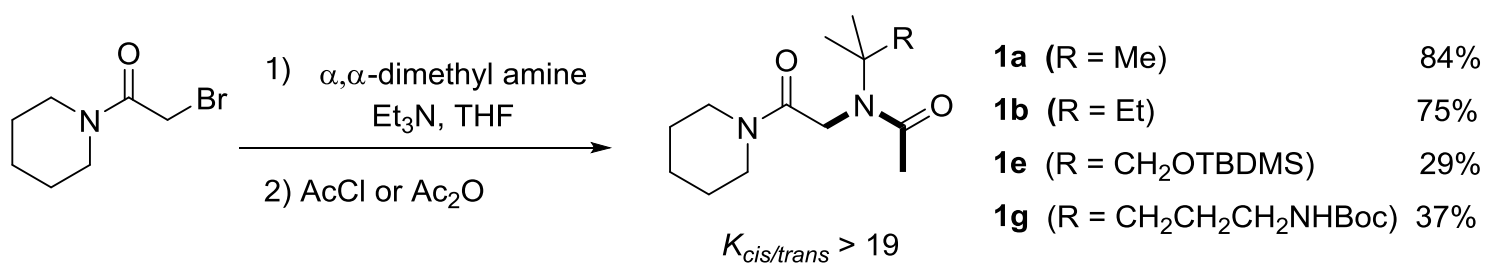

SCHEME 1 Synthesis of peptoid monomer models 1

As previously described, the steric effect of the tert-butyl group results in the presence of only one amide rotamer in the ${ }^{1} \mathrm{H}$ NMR spectra of monomer $1 \mathrm{a}$ in a variety of solvents $\left(\mathrm{CDCl}_{3}, \mathrm{CD}_{3} \mathrm{CN}\right.$, $\mathrm{CD}_{3} \mathrm{OD}$, acetone- $\mathrm{d}_{6}$, and $\mathrm{D}_{2} \mathrm{O}$, Supporting Information). This conformation was shown to be cis by NOESY experiments. ${ }^{14}$ The absence of the trans rotamer signals was therefore interpreted as the tertbutyl group resulting in a cis/trans ratio of $>$ 95:5 ( $K_{\text {cis/trans }}$ ratio $\left.>19\right)$. Importantly, the ${ }^{1} \mathrm{H}$ NMR spectra of the new peptoid models $\mathbf{1 b}, \mathbf{1 e}$ and $\mathbf{1 g}$ likewise only showed a single set of signals, corresponding to the cis conformation of the acetamide ( $K_{\text {cistrans }}$ ratio $\left.>19\right)$.

The cis inducing effect of the NCa-gem-dimethyl side chains was further studied on trimeric peptoids. A series of trimers with two consecutive tert-butyl side chains and a $N C \alpha$-gem-dimethyl side chain on the terminal acetamide was therefore designed. The trimer models 4-8 (Scheme 2) were prepared following the submonomer solution-phase synthesis methodology using a bromoacetic anhydridebased protocol developed for sterically hindered and deactivated primary amines. ${ }^{14}$ When using these optimized conditions and when employing volatile primary amines, chromatography is only required after the acylation step. ${ }^{27}$ Indeed, only filtration of salts and evaporation are needed after the substitution step. However, when a non-volatile primary amine is used in the substitution reaction, purification by flash chromatography is also required after this step. The use of solid-phase synthesis was avoided since it is our experience that oligomers of different lengths that are difficult to separate are obtained when synthesizing homooligomeric peptoids with $t \mathrm{Bu}$ side chains. The common bromo intermediates 2 and $\mathbf{3}$ were prepared in four steps starting from ethyl bromoacetate or benzyl bromoacetate with yields of $42 \%$ and $41 \%$, respectively (Scheme 2). Nucleophilic substitution using 
the $\alpha, \alpha$-gem-dimethyl amines $\mathbf{c}, \mathbf{d}, \mathbf{f}$ or $\mathbf{g}$ followed by acetylation provided trimers $\mathbf{4 - 8}$ (Table 1 ). Displacement of the bromide was also achieved with the non-gem-dimethylated amine $\mathbf{h}$ ( $N$-Boc-1,4diaminobutane) to provide peptoid $\mathbf{9}$ for comparative studies.
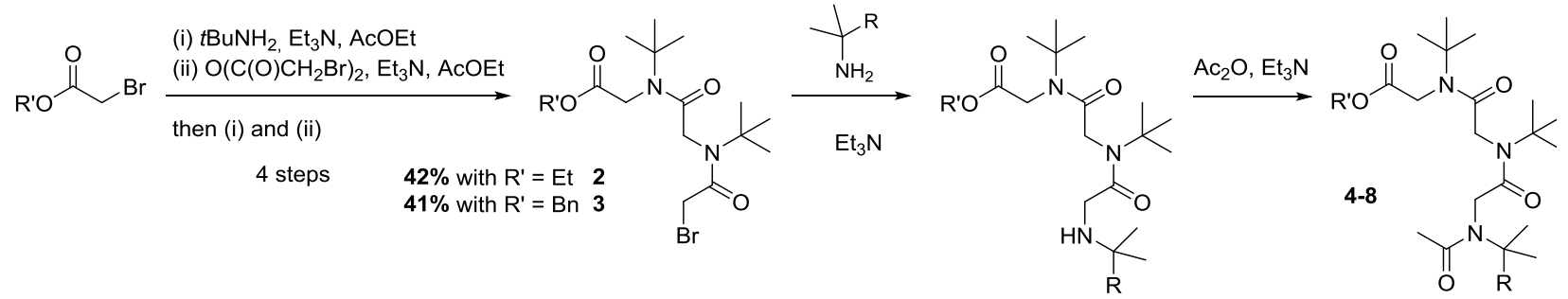

SCHEME 2 Synthesis of peptoid trimers 4-8 (conditions (i) for the substitution step and (ii) for the acylation step)

\begin{tabular}{|c|c|c|c|}
\hline Peptoid trimers & Amines & Yield $^{\mathrm{a}}$ & Exact mass HRMS (TOF MS ES+) \\
\hline Ac- $N g$ Phe- $N g h$ Ala- $N g h$ Ala-OEt 4 & $\mathbf{a}, \mathbf{a}, \mathbf{d}$ & $54 \%$ & $\mathrm{C}_{27} \mathrm{H}_{44} \mathrm{~N}_{5} \mathrm{O}_{3}\left[\mathrm{M}+\mathrm{H}^{+}\right]$: calc. 490.3270 , found 490.3275 \\
\hline Ac- $N g h$ Ser- $N g h$ Ala- $N g h$ Ala-OBn $\mathbf{5}$ & $\mathbf{a}, \mathbf{a}, \mathbf{c}$ & $72 \%$ & $\mathrm{C}_{27} \mathrm{H}_{44} \mathrm{~N}_{3} \mathrm{O}_{6}\left[\mathrm{M}+\mathrm{H}^{+}\right]$: calc. 506.3214 , found 506.3224 \\
\hline Ac-NghTrp-NghAla- $N g h$ Ala-OBn 6 & a, a, f & $74 \%$ & $\mathrm{C}_{35} \mathrm{H}_{49} \mathrm{~N}_{4} \mathrm{O}_{5}\left[\mathrm{M}+\mathrm{H}^{+}\right]$: calc. 605.3703 , found 605.3703 \\
\hline Ac- $N g$ Lys(Boc)- $N g h$ Ala- $N g h$ Ala-OEt 7 & a, a, $\mathbf{g}$ & $28 \%$ & $\mathrm{C}_{29} \mathrm{H}_{55} \mathrm{~N}_{4} \mathrm{O}_{7}\left[\mathrm{M}+\mathrm{H}^{+}\right]$: calc. 571.4065 , found 571.4053 \\
\hline Ac- $N g$ Lys(Boc)-NghAla- $N g h$ Ala-OBn 8 & & $54 \%$ & $\mathrm{C}_{34} \mathrm{H}_{57} \mathrm{~N}_{4} \mathrm{O}_{7}\left[\mathrm{M}+\mathrm{H}^{+}\right]$:calc. 633.4227 , found 633.4224 \\
\hline Ac- $N$ Lys(Boc)-NghAla-NghAla-OBn 9 & $\mathbf{a}, \mathbf{a}, \mathbf{h}^{\mathrm{b}}$ & $57 \%$ & $\mathrm{C}_{32} \mathrm{H}_{53} \mathrm{~N}_{4} \mathrm{O}_{7}\left[\mathrm{M}+\mathrm{H}^{+}\right]$:calc. 605.3909 , found 605.3892 \\
\hline
\end{tabular}

TABLE 1 Peptoid sequences and yields of trimers 4-9

The cis/trans ratio of the terminal acetamide was determined for all the trimer peptoids 4-9 by ${ }^{1} \mathrm{H}$ NMR integration of singlets corresponding to the acetyl $\mathrm{CH}_{3}$ protons (Figure 4). According to previous studies, ${ }^{19,28}$ the protons of trans peptoid acetamides are deshielded which results in a chemical shift of $>2 \mathrm{ppm}$. On the contrary, it was observed that the protons of cis acetamides display a chemical shift of $<2$ ppm. The ${ }^{1} \mathrm{H}$ NMR spectrum of trimer 9 in $\mathrm{CD}_{3} \mathrm{OD}$ showed two singlets at 1.93 and $2.15 \mathrm{ppm}$ in 48:52 proportion, indicating the presence of two conformational isomers in a 48:52 cis/trans ratio. By contrast, the ${ }^{1} \mathrm{H}$ NMR spectrum in $\mathrm{CD}_{3} \mathrm{OD}$ of the corresponding trimer $\mathbf{8}$ with a NC $\alpha$-gemdimethylated-functionalized lysine side chain showed a major singlet at $1.91 \mathrm{ppm}$ indicating a strong preference for the cis conformation of the terminal acetamide. A very small singlet detected at 2.15 ppm may correspond to the trans rotamer $(<3 \%)$. The same trend was observed for trimers $\mathbf{4 , 5 , 6}$, and 7 carrying the NCa-gem-dimethylated-functionalized phenylalanine, homo-serine, homo-tryptophan and lysine side chains respectively (Figure 4).

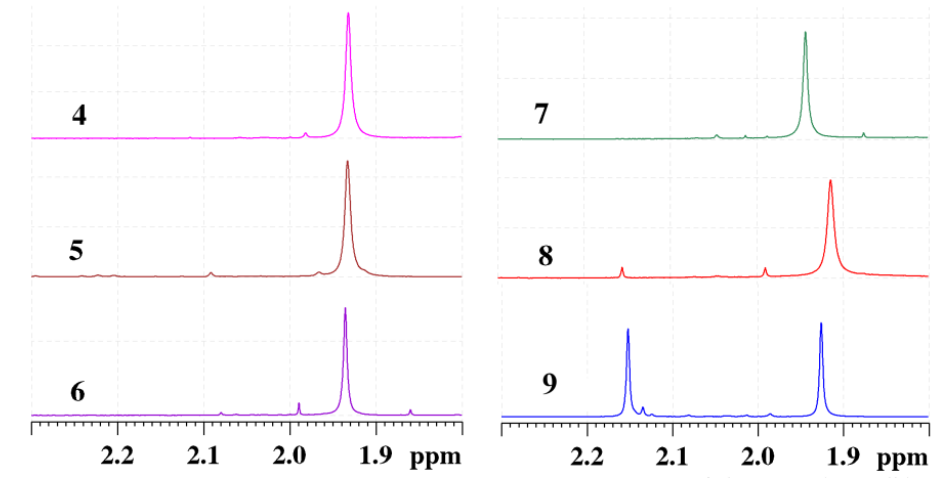

FIGURE 4 Acetyl proton region of the ${ }^{1} \mathrm{H}$ NMR spectra of trimers $\mathbf{4 , 5 , 6}$ (on the left) and $\mathbf{7 , 8 , 9}$ (on the right) in $\mathrm{CD}_{3} \mathrm{OD}$

This NMR study on model trimers clearly indicates that the $N C \alpha$-gem-dimethylated side chains have the same highly selective cis-directing effect as the tert-butyl side chain. This novel family of side chains thus locks the backbone amides in the cis conformation while maintaining access to a high 
degree of diversity. To further demonstrate the value of $N C \alpha$-gem-dimethylated side chains in a drug discovery context we therefore synthesized longer oligomers.

Access to longer oligomers was first explored using the submonomer method. This method was thus used to synthesize peptoid hexamer 14 carrying three different types of $N C \alpha$-gem-dimethylated residues: $\mathrm{NgPhe}, \mathrm{NgIle}$ and $\mathrm{N} g h \mathrm{Ser}$ (Scheme 3). The monomer $\mathbf{1 0}$ was first synthesized from tertbutyl bromoacetate and amine b. Five submonomer cycles then furnished the hexamer $\mathbf{1 3}$ in a nonoptimized overall yield of $10 \%$. Subsequent acetylation using acetic anhydride and tertbutyldimethylsilyl deprotection with tetrabutylammonium fluoride furnished the hexapeptoid Ac$(\mathrm{NghSer}-\mathrm{NgPhe}-\mathrm{NgIle})_{2}-\mathrm{O} t \mathrm{Bu} \mathbf{1 4}$ as a white powder.
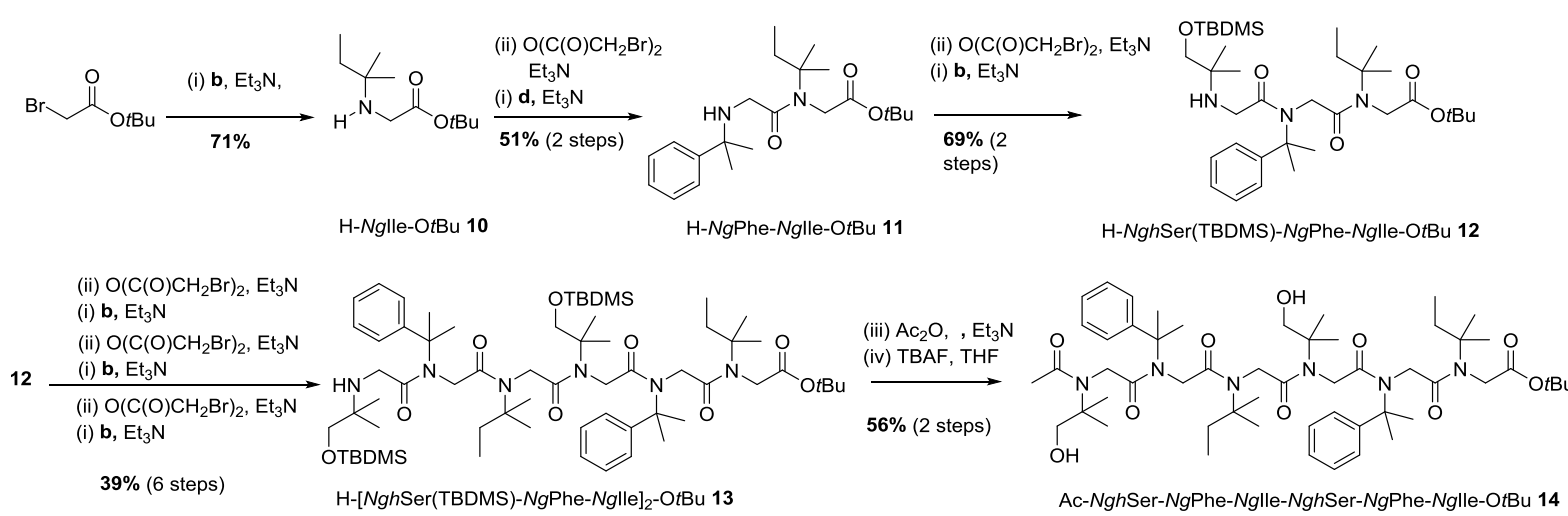

SCHEME 3 Submonomer synthesis of peptoid hexamer Ac- $(N g h \mathrm{Ser}-N g \text { Phe- } N g I l e)_{2}-\mathrm{O} t \mathrm{Bu} 14$ (conditions (i) for the substitution step and (ii) for the acylation step; all oligomers present amide bonds in a dominant cis conformation, but are drawn trans for convenience)

A convergent fragment-coupling approach which is more appropriate to access longer oligomers was then explored. Using this method, hexamer 18 was synthesized (Scheme 4). First, the trimer block amine 15 and trimer block acid $\mathbf{1 7}$ were prepared by submonomer synthesis, incorporating successively the amines $\mathbf{b}$ (tert-amylamine), $\mathbf{d}$ ( $\alpha, \alpha$-dimethylbenzylamine) and $\mathbf{a}$ (tert-butylamine). The coupling of these two trimers using FDPP as coupling reagent in the presence of 1,8diazabicyclo[5.4.0]undec-7-ene (DBU) as base, yielded the hexamer 18 in $44 \%$ yield. The use of a two-step procedure involving the corresponding activated pentafluorophenyl ester intermediate ${ }^{19}$ instead proved less efficient. Indeed, only $12 \%$ of hexamer $\mathbf{1 8}$ was formed and nearly $50 \%$ of the trimer block amine 15 was recovered after purification of the crude product.
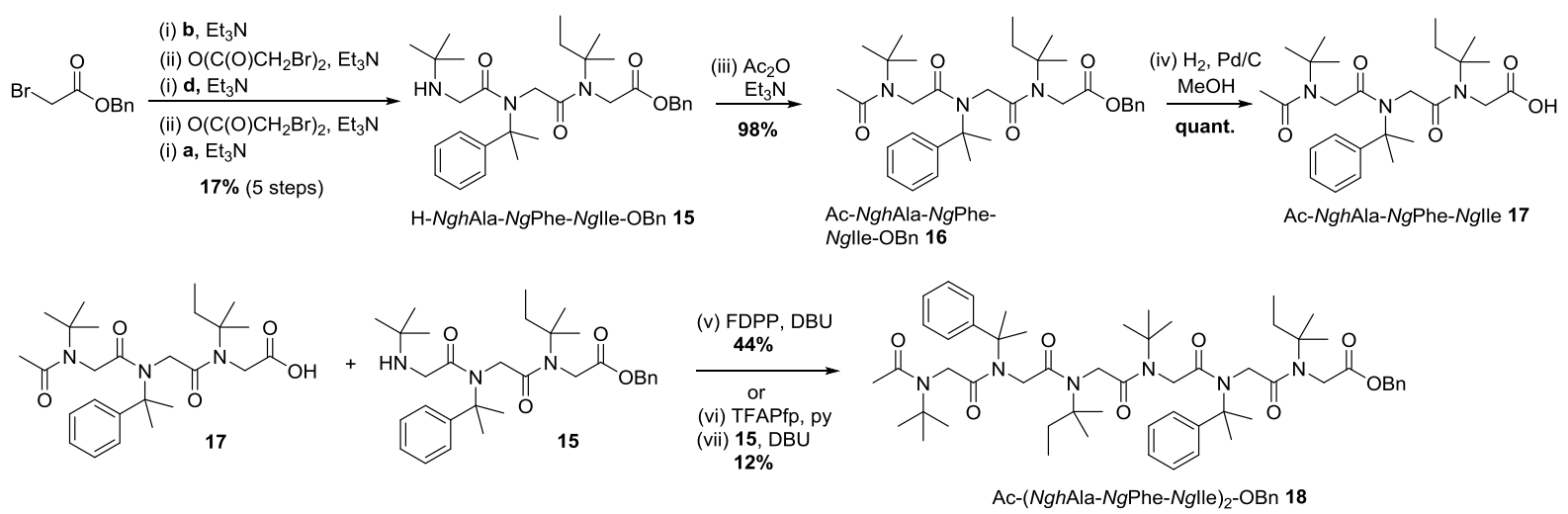

SCHEME 4 Fragment-coupling approach to access peptoid hexamer Ac-( $\mathrm{NghAla-NgPhe-NgIle)})_{2}-\mathrm{OBn} 18$ (conditions (i) for the substitution step and (ii) for the acylation step; all oligomers present amide bonds in a dominant cis conformation, but are drawn trans for convenience) 
In order to provide insight into the preferred orientation of the substituents of the NC $\alpha$-gem-dimethyl side chains with respect to the peptoid backbone, the total energy of peptoid models with the acetamide in the cis conformation was determined by a systematic variation of the $\chi 1$ torsion angle by intervals of $5^{\circ}$ at the B3LYP/6-31+G(d,p) level (Figure 5). The calculations were performed on $C$ methyl ester peptoid monomers capped with an acetyl group at the $N$-terminus with different $N C \alpha$ gem-dimethyl side chains (models Ac-NtBu-OMe, Ac-NgIle-OMe and Ac- $N g$ Phe-OMe) or the isopropyl group (model Ac-NiPr-OMe).

(A)

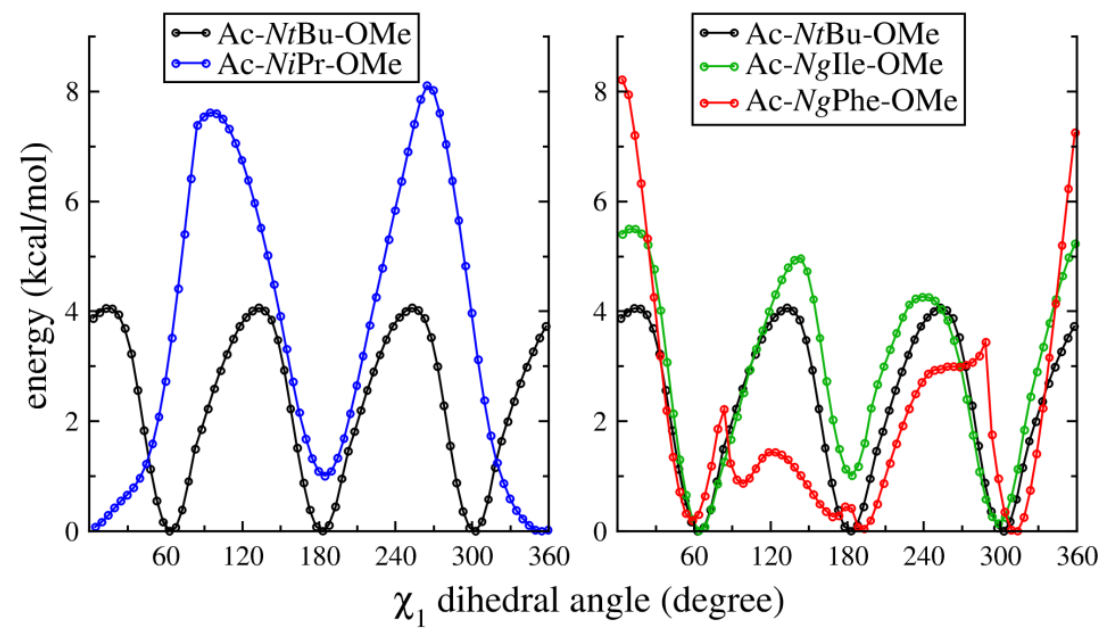

(C)

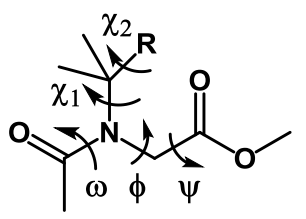

$$
\begin{aligned}
& \mathrm{R}=\mathrm{CH}_{3} \text { for } \mathrm{Ac}-\mathrm{NtBu}-\mathrm{OMe} \\
& \mathrm{R}=\mathrm{H} \text { for } \mathrm{Ac}-\mathrm{NiPr}-\mathrm{OMe} \\
& \mathrm{R}=\mathrm{Et} \text { for } \mathrm{Ac}-\mathrm{Ng} \text { lle-OMe } \\
& \mathrm{R}=\mathrm{Ph} \text { for } \mathrm{Ac}-\mathrm{Ng} \text { Phe-OMe }
\end{aligned}
$$

FIGURE 5 Energy diagram of the total scan of the $\chi_{1}$ dihedral angles of model peptoid monomers: (A) Models carrying the tert-butyl side chain $(\mathrm{R}=\mathrm{Me})$ in black and the isopropyl side chain $(\mathrm{R}=\mathrm{H})$ in blue; (B) Models carrying the tert-butyl side chain $(\mathrm{R}=\mathrm{Me})$ in black, the $N C \alpha$-gem-dimethyl propyl side chain $(\mathrm{R}=\mathrm{Et})$ in green and the $N C \alpha$-gem-dimethyl benzyl side chain $(\mathrm{R}=\mathrm{Ph})$ in red; $(\mathrm{C})$ Chemical structure of the models and definition of the dihedral angles : $\omega\left[\mathrm{C}_{\alpha}(i-1) ; \mathrm{C}(i-1) ; \mathrm{N} ; \mathrm{C}_{\alpha}\right], \Phi$ $\left.\left[\mathrm{C}(i-1) ; \mathrm{N} ; \mathrm{C}_{\alpha} ; \mathrm{C}\right], \Psi\left[\mathrm{N} ; \mathrm{C}_{\alpha} ; \mathrm{C} ; \mathrm{O}\right], \chi_{1}\left[\mathrm{C}(i-1) ; \mathrm{N} ; \mathrm{NC}_{\alpha} ; \mathrm{NC}_{\beta} \mathrm{R}\right)\right]$ or $\left.\left[\mathrm{C}(i-1) ; \mathrm{N} ; \mathrm{NC}_{\alpha} ; \mathrm{H}\right)\right]$ for the Ac-NiPr-OMe model

As recently reported, the side chain $\chi 1$ dihedral angle of $\mathrm{N} t \mathrm{Bu}$ peptoid units differs significantly from that of peptoid monomers bearing a disubstituted side chain such at the $\mathrm{NC}_{\alpha}$ carbon as for example an isopropyl side chain. ${ }^{19}$ For the Ac-N $t \mathrm{Bu}-\mathrm{OMe}$ model, three minima of equal energies were observed on the energy diagram for $\chi_{1}$ values around $+60^{\circ}, \pm 180^{\circ}$ and $-60^{\circ}\left(300^{\circ}\right)$ (Figure 5A). These staggered conformations prevent steric clashes between the Me groups and the amide carbonyl group of residue (i-1). By contrast, for the Ac-NiPr-OMe model, two minima were observed for $\chi_{1}$ values around $0^{\circ}$ and $\pm 180^{\circ}$. The lowest energy minimum corresponds to the eclipsed conformation with the $N \mathrm{C}_{\alpha}-\mathrm{H}$ bond facing the $\mathrm{C}=\mathrm{O}$ bond. For the Ac-NgIle-OMe model, three minima were observed corresponding to those observed for the Ac-NtBu-OMe model. The two lowest energy minima correspond to gauche conformations $\left(+60^{\circ}\right.$ and $\left.-60^{\circ}\left(300^{\circ}\right)\right)$ and the third minimum corresponds to the anti-conformation $\left(180^{\circ}\right)$ (Figure 5B). The anti-conformation is $1 \mathrm{kcal} / \mathrm{mol}$ higher in energy than the gauche conformation due to a small steric clash between the ethyl $\mathrm{CH}_{3}$ group and the backbone $\mathrm{C}_{\alpha}$ protons. For the Ac- $\mathrm{NgPhe}-\mathrm{OMe}$ model, three minima centered at about $+60^{\circ}, \pm 180$ and $-60^{\circ}\left(300^{\circ}\right)$ were also observed, but the profile of the energy diagram between these minima is unique. In this case, the $\chi_{2}$ dihedral angle corresponding to the phenyl group rotation is also an important factor. However, the three lowest energy minima correspond to those observed for the Ac- $N t \mathrm{Bu}-\mathrm{OMe}$ model.

Peptoid oligomers with cis-amide bonds adopt a structure similar to the polyproline type I helix and the helical screw sense is induced by the stereochemistry of $\alpha$-chiral side chains. Recently, we reported that achiral $\mathrm{N} t \mathrm{Bu}$-based peptoids may also adopt a PPI-like structure stabilized by weak backbone $\mathrm{CH}^{\cdots} \mathrm{O}=\mathrm{C}$ interactions and side chain $t \mathrm{Bu}^{\cdots} t \mathrm{Bu}$ London interactions. ${ }^{19}$ The same should be 
observed in peptoid oligomers comprised of $N C \alpha$-gem-dimethylated units. We have therefore performed a $40 \mathrm{~ns}$ molecular dynamic (MD) simulation of peptoid hexamer 18. The initial structure was generated with backbone dihedral angles $(\omega, \Phi, \Psi)=\left(0^{\circ},-90^{\circ}, \pm 180^{\circ}\right)$ near the polyproline type I helix and the side chain $\chi_{1}$ dihedral angles were chosen according to the energy minima observed during the scan of the $\chi_{1}$ dihedral angle. The $\chi_{1}$ values were therefore initially fixed at $+60^{\circ}$ for the $N t \mathrm{Bu}$ units, at $\pm 180^{\circ}$ for the $N g$ Phe units and at $-60^{\circ}$ for the $N g I l$ units. In the course of the MD simulation, the helical conformation was maintained revealing the stability of this structuration that closely resembles the PPI helix (Figure 6 and Supporting Information Figure S3).

(A)

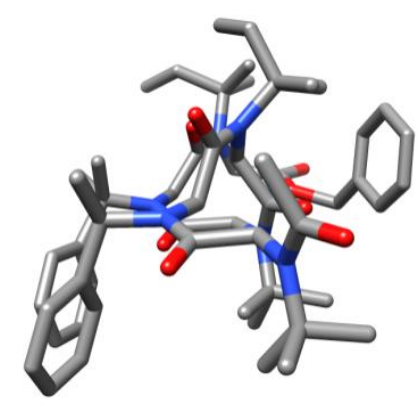

(B)

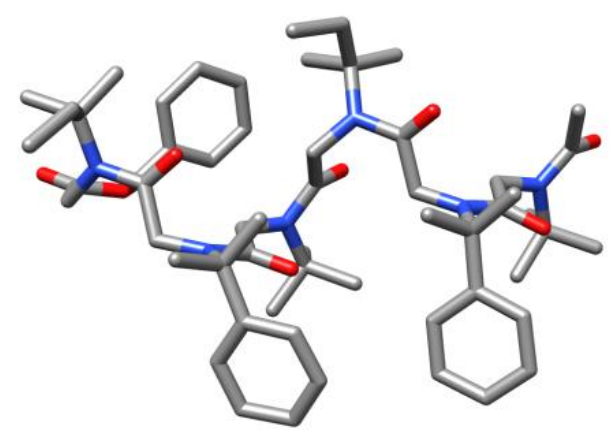

FIGURE 6 Model of hexamer 18 obtained by molecular dynamic (A) view perpendicular to the helical axis and (B) view parallel to the helical axis

Monitoring of the $\chi_{1}$ dihedral angle variation over the course of the simulation as expected showed that rotation of the tert-butyl group occurred with three privileged positions $\left(\chi_{1}=+60^{\circ},-60^{\circ}\right.$ or $\left.180^{\circ}\right)$ (Supporting Information Figure S2). By contrast, in the case of the NCa-gem-dimethylated side chains no rotation was observed during the simulation, apart from in the very beginning. Indeed, the $\chi_{1}$ dihedral angle for the $\mathrm{Ng}$ Phe units rapidly reached approximately $-60^{\circ}$, which is identical to those of the $N g$ Ile units. This $\chi_{1}$ dihedral angle of $-60^{\circ}$ corresponds to a spatial arrangement where the $\mathrm{R}$ substituents of the $N C \alpha$-gem-dimethylated side chains are pointing away from the helical axis. According to this model, the formation of a PPI-like helical structure with outward distribution of the $\mathrm{R}$ groups is thus favored for peptoid oligomers incorporating NC $\alpha$-gem-dimethylated side chains.

\section{CONCLUSION}

We have shown the high cis-directing effect of $N C \alpha$-gem-dimethylated side chains by NMR spectroscopy studies of monomeric and trimeric peptoid models. Hexamers carrying NC $\alpha$-gemdimethylated side chains were furthermore obtained in solution by the submonomer method or a convergent fragment-coupling approach. The privileged positioning of the $\mathrm{R}$ group of the NCa-gemdimethylated side chains was scrutinized according to the $\chi 1$ torsion angle value by determining the total energy of peptoid models with the acetamide in the cis conformation. As observed for the tertbutyl side chain, staggered conformations preventing steric clashes between the methyl groups and the amide carbonyl group of residue (i-1) were preferred. A model of the PPI-type helix was constructed and studied by molecular dynamics simulations. This helical conformation appeared to be highly favorable although the achiral side chains do not allow controlling the helix direction i.e. the sign of $\Phi$ dihedral angle $\left(\approx-90^{\circ}\right.$ or $\left.+90^{\circ}\right)$. ${ }^{19}$ Indeed in peptoid folding, the chirality of the side chains is critical to get well-folded secondary structures of defined handedness. This aspect has to be taken into account in the future design of $N C \alpha$-gem-dimethylated $N$-substituted glycine oligomers mimicking specific peptide sequences. 
Overall, these novel $N C \alpha$-gem-dimethylated side chains represent a valuable addition to the "toolbox" for the construction of folded functionalized peptoid oligomers. This family of side chains retains structural diversity while maintaining a high degree of conformational control. The close mimic of peptide sequence is a crucial subject in a drug discovery context and these novel side chains will, for example, enable careful structure-activity relationship studies in the domain of peptoid-protein recognition.

\section{ACKNOWLEDGMENT}

We gratefully thank the French Ministry of Higher Education and Research for the grant to RS. We are grateful to M. Leremboure for mass spectrometry analysis (UCA PARTNER).Computations have been performed on the supercomputer facilities of the Mésocentre Clermont Auvergne. This work was supported by the ANR project ARCHIPEP.

\footnotetext{
${ }^{1}$ R. N. Zuckermann, J. M. Kerr, S. B. H. Kent, W. H. Moos, J. Am. Chem. Soc. 1992, 114, 10646.

${ }^{2}$ A. S. Culf, R. J. Ouellette, Molecules 2010, 15, 5282.

${ }^{3}$ R. N. Zuckermann, T. Kodadek, Curr. Opin. Mol. Ther.2009, 11, 299.

${ }^{4}$ C. W.Wu, K. Kirshenbaum, T. J. Sanborn, J. A. Patch, K. Huang, K. A. Dill, R. N. Zuckermann, A. E. Barron, J. Am. Chem.Soc. 2003, 125, 13525.
}

${ }^{5}$ N. H. Shah, G. L. Butterfoss, K. Nguyen, B. Yoo, R. Bonneau, D. L. Rabenstein, K. Kirshenbaum, J. Am. Chem. Soc. 2008, 130, 16622.

${ }^{6}$ B. C. Gorske, E. M. Mumford, C. G. Gerrity, I. Ko, J.Am.Chem.Soc. 2017, 139, 8070.

${ }^{7}$ J. A. Crapster, I. A. Guzei, H. E. Blackwell, Angew. Chem. Int. Ed. 2013, 52, 5079.

${ }^{8}$ K. Huang, C.W. Wu, T.J. Sanborn, J.A. Patch, K. Kirshenbaum, R.N. Zuckermann, A.E. Barron, I. Radhakrishnan, J. Am. Chem. Soc. 2006, 128, 1733.

${ }^{9}$ R. V. Mannige, T. K. Haxton, C. Proulx, E. J. Robertson, A. Battigelli, G. L. Butterfoss, R. N. Zuckermann, S. Whitelam, Nature 2015, 526, 415.

${ }^{10}$ R. Gopalakrishnan, A. I. Frolov, L. Knerr, W. J. Drury III, E. Valeur, J. Med. Chem. 2016, 59, 9599.

${ }^{11}$ B. C. Gorske, J. R. Stringer, B. L. Bastian, S. A. Fowler, H. E. Blackwell, J. Am. Chem. Soc. 2009, 131, 16555.

${ }^{12}$ C. Caumes, O. Roy, S. Faure, C. Taillefumier, J. Am. Chem. Soc. 2012, 134, 9553.

${ }^{13}$ O. Roy, G. Dumonteil, S. Faure, L. Jouffret, A. Kriznik, C. Taillefumier, J. Am. Chem. Soc. 2017, 139, 13533.

${ }^{14}$ O. Roy, C. Caumes, Y. Esvan, C. Didierjean, S. Faure, C. Taillefumier, Org. Lett. 2013, 15, 2246.

${ }^{15}$ D. Gimenez, J. A. Aguilar, E. H. C. Bromley, S. L. Cobb, Angew. Chem. Int. Ed. 2018, 57, 10549.

${ }^{16} \mathrm{~J}$. Seo, A. E. Barron, R. N. Zuckermann, Org. Lett. 2010, 12, 492.

${ }^{17}$ R. Shyam, N. Charbonnel, A. Job, C. Blavignac, C. Forestier, C. Taillefumier, S. Faure, ChemMedChem 2018, 13, 1513.

${ }^{18}$ G. Dumonteil, N. Bhattacharjee, G. Angelici, O. Roy, S. Faure,L. Jouffret, F. Jolibois, L. Perrin, C. Taillefumier, J. Org. Chem. 2018, 83, 6382.

${ }^{19} \mathrm{G}$. Angelici, N. Bhattacharjee, O. Roy, S. Faure, C. Didierjean, L. Jouffret, F. Jolibois, L. Perrin, C. Taillefumier, Chem. Commun. 2016, 52, 4573.

${ }^{20}$ T. T. Talele, J. Med. Chem. 2018, 61, 2166.

${ }^{21}$ C. Toniolo, M. Crisma, F. Formaggio, C. Peggion, J. Pept. Sci. 2001, 60, 396.

${ }^{22}$ Gaussian 09, Revision D.01, M. J. Frisch, G. W. Trucks, H. B. Schlegel, G. E. Scuseria, M. A. Robb, J. R. Cheeseman, G. Scalmani, V. Barone, G. A. Petersson, H. Nakatsuji, X. Li, M. Caricato, A. Marenich, J. Bloino, B. G. Janesko, R. Gomperts, B. Mennucci, H. P. Hratchian, J. V. Ortiz, A. F. Izmaylov, J. L. Sonnenberg, D. WilliamsYoung, F. Ding, F. Lipparini, F. Egidi, J. Goings, B. Peng, A. Petrone, T. Henderson, D. Ranasinghe, V. G.

Zakrzewski, J. Gao, N. Rega, G. Zheng, W. Liang, M. Hada, M. Ehara, K. Toyota, R. Fukuda, J. Hasegawa, M. Ishida, T. Nakajima, Y. Honda, O. Kitao, H. Nakai, T. Vreven, K. Throssell, J. A. Montgomery, Jr., J. E. Peralta, F. Ogliaro, M. Bearpark, J. J. Heyd, E. Brothers, K. N. Kudin, V. N. Staroverov, T. Keith, R. Kobayashi, J. Normand, K. Raghavachari, A. Rendell, J. C. Burant, S. S. Iyengar, J. Tomasi, M. Cossi, J. M. Millam, M. Klene, C. Adamo, R. Cammi, J. W. Ochterski, R. L. Martin, K. Morokuma, O. Farkas, J. B. Foresman, and D. J. Fox, Gaussian, Inc., Wallingford CT, 2016.

${ }^{23}$ E. F. Pettersen, T.D. Goddard, C.C. Huang, G.S. Couch, D.M. Greenblatt, E.C. Meng, T.E. Ferrin, J. Comput. Chem. 2004, 25, 1605. 
${ }^{24}$ J.C. Phillips, R. Braun, W. Wang, J. Gumbart, E. Tajkhorshid, E. Villa, C. Chipot, R. D. Skeel, L. Kale, K. Schulten, J. Comput. Chem. 2005, 26, 1781.

${ }^{25}$ A.D. MacKerell, M. Feig, C.L. Brooks III, J. Comput.Chem. 2004, 25, 1400.

${ }^{26}$ W. Humphrey, A. Dalke, K. Schulten, J. Mol. Graphics 1996, 14, 33.

${ }^{27}$ C. Caumes, T. Hjelmgaard, R. Remuson, S. Faure, C. Taillefumier, Synthesis 2011, 2, 257.

${ }^{28} \mathrm{H}$. Aliouat, C. Caumes, O. Roy, M. Zouikri, C. Taillefumier, S. Faure, J. Org. Chem. 2017, 82, 2386. 